\title{
MATHEMATICAL MODEL OF HYDROLYSIS REACTION FOR THE COLLAGEN HYDROLYZATE PRODUCTION FROM LEATHER SHAVINGS
}

\author{
Hana Vaskova \& Vladimir Vasek
}
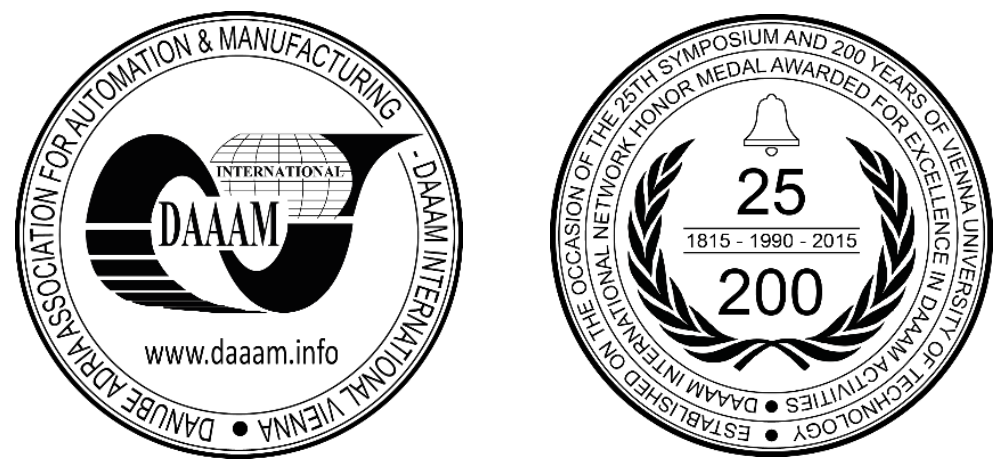

This Publication has to be referred as: Vaskova, H[ana] \& Vasek, V[ladimir] (2016). Mathematical Model of Hydrolysis Reaction for the Collagen Hydrolyzate Production From Leather Shavings, Proceedings of the 27th DAAAM International Symposium, pp.0271-0274, B. Katalinic (Ed.), Published by DAAAM International, ISBN 9783-902734-08-2, ISSN 1726-9679, Vienna, Austria DOI: $10.2507 / 27$ th.daaam.proceedings.040

\begin{abstract}
An integral part of the automated control implementation is mathematical description of the basic processes and mathematical modeling. In this paper, the mathematical model for alkaline hydrolysis of shavings, a leather waste material, is presented. Leather industry produces annually a large amount of wastes. For the environment-friendly solution it is efficient to process the certain part of wastes arising from the leather industry. Collagen protein contained in e.g. leather shavings can be further utilized. Hydrolysis processes seems to be reasonable solution. The description of the hydrolysis process is based on the linearized state model. The mathematical-physical model is built on the mass balance of the input substances and the resulting hydrolyzate protein, moreover on an enthalpy balance for the reaction mixture and saturated steam serving in reactor as the heat transfer medium.
\end{abstract}

Keywords: Mathematical modeling; hydrolysis; leather; waste; automatic control.

\section{Introduction}

The topic of waste management and waste processing is widely discussed topic nowadays. A significant amount of waste is in the leather industry. The leather tanning industry is historically one of the first industries occupying an important function in terms of by-products of other industry - meat industry. However, it is also perceived as a resources consumer and pollutants producer [1]. Tanning industry transforms raw hides of slaughter and game animals through physical and chemical processes to a stable, technically usable product - the leather. On one hand it uses meat industry waste as a feedstock on the other hand this industry produces another hazardous waste.

Production of $200 \mathrm{~kg}$ of leather requires one ton of raw hides processing, i.e. feedstock usage is only $20 \%$ efficient. From this one ton of raw hides about $250 \mathrm{~kg}$ of non-tanned waste, $200 \mathrm{~kg}$ of tanned wastes containing chromium is also produced. The remaining share comprises modified solid waste and sludge. In the production of $200 \mathrm{~kg}$ of leather about $50,000 \mathrm{~kg}$ of waste water containing about $5 \mathrm{~kg}$ of chromium is generated. Approximately 10 million tons of raw hide is processed annually [2]. 
Another topic comprising toxic hexavalent chromium and the ways of its transformation from and into trivalent form is closely related with the production of leather and with the area of tannery waste disposal. This topic should not be neglected in terms of human health, the environment [3] and the detection of harmless substances [4].

Mathematical modeling gains a great importance for the analysis and prediction of the behaviour of processes and phenomena in areas of natural, technical, industrial, but also economic and social in recent years. It offers the possibility to transfer the problem from the field of application to be processed mathematically. This allows to penetrate through the analysis into its nature and to obtain useful information about investigated problem. Using mathematical means and information technology, procedures leading to deeper and more thorough understanding can be created.

The literature search shows, that the automatic control in leather/hide processing respectively leather waste processing is not very widespread. The most literary sources talks rather about the use of automated and robotic devices in secondary manufacturing industries. These sectors include especially footwear industry, which process over the half of the produced leather, textile industry and extensive use is also for upholstery and automotive industry.

The level of measurement and control systems applications is low due to the lack of quantitative models allowing the use of some modern control methods. However, in recent years, efforts are being made to implement the automation into the leather processing to increase productivity, precision of operations, time efficiency and last but not least to reduce physically demanding work, restrict acts of the health hazards of employees and contribute to the work environment improvement.

The problems of processing the leather industry wastes including proposals for technological devices equipped with automatic control are solved in last decades at our workplace, at the Faculty of Applied Informatics at Tomas Bata University in Zlín, Czech Republic [5], [6] and [7].

\section{Leather waste processing}

\subsection{Waste treatment process}

The complex processing of leather shavings can be, in simplified way, divided into three stages as is shown in Fig. 1 (left). Collagen protein is liquefied and separated from the chromium sludge in the first stage. Chromium sludge can be subjected to revitalization for obtaining chromium in a form of salts for further leather tanning [8]. One part of resulting gelatinous protein, a high-quality gelatine finds cost-effective usage applications such as in pharmacy, food industry, or cosmetics. The rest of gelatinous protein is used for further processing. Enzyme activity leads in alkaline conditions to molar mass decrease of gelatinous hydrolyzate. Further splitting of protein chain can continue by the act of acid. The hydrolyzate with lower molar mass is acquired subsequently and can find application in agriculture.
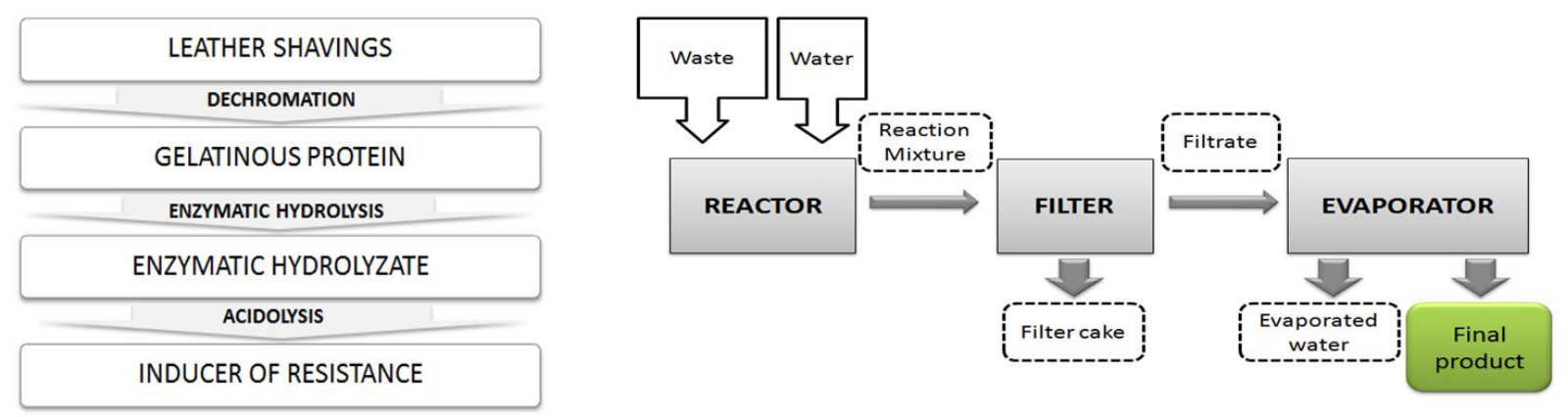

Fig. 1. The structure of collagen protein hydrolysis (left). The diagram of the production system (right)

\subsection{Production system}

The production system for producing the hydrolyzate is composed of three basic elements: the reactor, the filter and the vacuum evaporator. The simplified diagram is shown in Fig. 1 (right). Feedstocks in the reactor are leather waste, water and an alkali, creating a reaction mixture. When the desired degree of hydrolysis is reached, hot heterogeneous mixture is filtered and the resulting filtrate is further transferred to an evaporator, where the concentration of hydrolysed substance is increased.

\section{Mathematical model}

For the process description the linearized state mathematical model including input, output variables and inner-state variables is used. Linearized model is obtained by introducing deviations of state and input variables from their stationary states and then linearized using Taylor series. The detailed mathematical treatments are presented in [3] Continuous linear system is described by the state equation and output status 


$$
\begin{aligned}
& \Delta \dot{\mathbf{X}}=\mathbf{A} \Delta \mathbf{X}+\mathbf{B} \Delta \mathbf{U} \\
& \Delta \mathbf{Y}=\mathbf{C} \Delta \mathbf{X}+\mathbf{D} \Delta \mathbf{U}
\end{aligned}
$$

where $\mathrm{A}$ is state matrix, $\operatorname{dim} \mathrm{A}=n \times n, \mathrm{~B}$ is the input matrix, $\operatorname{dim} \mathrm{B}=n \times r, \mathrm{C}$ is the output matrix, $\operatorname{dim} \mathrm{C}=m \times n, \mathrm{D}$ is the zero matrix, $\operatorname{dim} \mathrm{D}=\mathrm{m} \times r$.

This system as a real system fulfils the strong physical condition of the feasibility, i.e. the outputs are functions only of the state variables. This means that for

$$
\Delta \mathbf{Y}=\Delta \mathbf{X}
$$

the matrix $\mathrm{C}$ is the identity matrix and $\mathrm{D}$ is the zero matrix.

Mathematical-physical model for alkaline hydrolysis of shavings is based on the mass balance of the input substance, the resulting hydrolyzate protein, enthalpy balance for the reaction mixture and the heat transfer medium. As a heat transfer medium the saturated steam is considered. The hydrolysis process takes place in a flow reactor with a stirrer ensuring the state variable independence on the position in the reactor. It is considered as system with lumped parameters. The mixing the heat transfer medium is also presumed. The mathematical model is given by the balance equations (4) - (7). The used symbols are specified in Table 1.

\begin{tabular}{|l|l|l|}
\hline Symbol & \multicolumn{1}{|c|}{ Physical quantity } & \multicolumn{1}{|c|}{ Unit } \\
\hline$m_{R}$ & Mass of reaction mixture (RS) & $\mathrm{kg}$ \\
\hline$m_{P}$ & Mas of water & $\mathrm{kg}$ \\
\hline$\cdot$ & Mass flow of reaction mixture & $\mathrm{kg} / \mathrm{s}$ \\
\hline$m_{R S}$ & & $\mathrm{~kg} / \mathrm{s}$ \\
\hline$m_{P}$ & Mass flow of heating stem, respectively water & 1 \\
\hline$a_{P}$ & Initial mass fraction of protein in RS & 1 \\
\hline$a_{B}$ & Mass fraction of decomposed protein in the reactor & 1 \\
\hline$a_{E}$ & Mass fraction of undecomposed protein in the reactor & $\mathrm{K}$ \\
\hline$T_{R S}$ & Temperature of RS & $\mathrm{K}$ \\
\hline$T_{0}$ & Temperature of stem, the output & $\mathrm{K}$ \\
\hline$T$ & Temperature of the reactor shell = temperature of water, the output & $\mathrm{J} / \mathrm{kgK}$ \\
\hline$c_{R S}$ & Specific heat of RS & $\mathrm{J} / \mathrm{kgK}$ \\
\hline$c_{P}$ & Specific heat of water & $\mathrm{W} / \mathrm{m}^{2} \mathrm{~K}$ \\
\hline$K$ & Heat transfer coefficient & $\mathrm{m}{ }^{2}$ \\
\hline$S$ & Area of reactor heated by steam & $\mathrm{J} / \mathrm{kg}$ \\
\hline$H$ & Specific latent heat of vaporization & \\
\hline
\end{tabular}

Table 1. Variables used in the model

Mass balance for protein

$$
m_{R S} a_{P}=m_{R S} a_{B}+k m_{R} a_{B}+m_{R} \frac{\mathbf{d} a_{B}}{\mathbf{d} t}
$$

Mass balance for hydrolyzate

$$
0=m_{R S} a_{E}-k m_{R} a_{B}+m_{R} \frac{\mathbf{d} a_{E}}{\mathbf{d} t}
$$

Enthalpy balance for reaction mixture

$$
\dot{m}_{R S} c_{R S} T_{R S}+K S\left(T-T_{R}\right)=\dot{m}_{R S} c_{R S} T_{R}+m_{R} c_{R S} \frac{\mathbf{d} T_{R}}{\mathbf{d} t}
$$

Enthalpy balance for heat transfer fluid

$$
\dot{m}_{P} H+\dot{m}_{P} c_{P} T_{0}=\dot{m}_{P} c_{P} T+K S\left(T-T_{R}\right)+m_{P} c_{P} \frac{\mathbf{d} T}{\mathbf{d} t}
$$

Taking the Laplace transforms of (1) and (2) together with (3) we get

$$
G(s)=(s I-A)^{-1} B
$$


Expression of matrices A and B is then based on the mathematic model (4) - (7). The transfer matrix is calculated from (8). Transferred to the dimensionless form and expressed using values of physical quantities for a real reactor we got a matrix $\mathrm{G}^{*}$ depicted in equation (9).

$$
G^{*}=\left[\begin{array}{ccccc}
\frac{1}{4,09+s} & \frac{0,27}{4,09+s} & 0 & 0 & 0 \\
\frac{3,09}{4,09+5,09+s^{2}} & -\frac{0,27+0,27 s}{4,09+5,09+s^{2}} & 0 & 0 & 0 \\
0 & -\frac{50(22,75+s)}{343\left(28,13+29,13 s+s^{2}\right)} & \frac{22,75+s}{28,13+29,13 s+s^{2}} & \frac{3,44}{28,13+29,13 s+s^{2}} & \frac{2,17}{28,13+29,13 s+s^{2}} \\
0 & -\frac{227250}{343\left(28,13+29,13 s+s^{2}\right)} & \frac{4545}{28,13+29,13 s+s^{2}} & \frac{4,09+0,64 s}{28,13+29,13 s+s^{2}} & \frac{2,58+0,41 s}{28,13+29,13 s+s^{2}}
\end{array}\right]
$$

Simulations based on the state description concerning matrixes A and B and the calculated transfer matrix $\mathrm{G}$ were performed in Matlab Simulink. These simulations are not described within this paper.

\section{Conclusion}

Mathematical-physical model for the hydrolysis of collagen protein from tannery wastes is presented in the paper. This way of treatment offers safe, environmentally friendly method for the reduction of waste gained from leather manufacturing sector. Simulations of the model serves for further laboratory and pilot scale experiments and contribute to automated control of the production process. Further steps leads to the optimization of the main operating costs for the production of collagen hydrolyzate what brings another benefit in terms of economical effectivity.

\section{Acknowledgement}

This work was supported by the Ministry of Education, Youth and Sports of the Czech Republic within the National Sustainability Program project No. LO1303 (MSMT-7778/2014).

\section{References}

[1] Mwinyihija, Mwinyikione. (2010). Main Pollutants and Environmental Impacts of the Tanning Industry. Ecotoxicological Diagnosis in the Tanning Industry. New York, 978-1-4419-6266-9, NY: Springer New York

[2] http://www.fao.org/fileadmin/templates/est/MARKETS_MONITORING/HidesSkins.pdf World Statistical Compendium for raw hides and skins, leather and leather footwear 1993-2012, Accessed on: 2015-06-11

[3] Vaskova, H. (2015) Modeling of chemical reactor for leather waste dechromation. Ph.D. Dissertation, Tomas Bata Univerzity in Zlin, Czech Republic

[4] Vašková, H. (2010) Raman spectroscopy: a modern technique for material properties identification. Proceedings of the 21st International DAAAM Symposium 2010 Zadar, Croatia. Vienna: DAAAM International Vienna, pp. 13211322. ISBN 978-3-901509-73-5

[5] Vašek, V., Dolinay, J., Dostálek, P., Janáčová, D., Kolomazník K. (2009). Microcontrollers in Tannery Waste Recycling Control. 1th International Leather Engineering Symposium "Leather Industry, Environment and Progressive Technologies". Izmir, Age University

[6] Kolomazník, K., Vašek, V., Janáčová, D. (2009). Control recycling technology of tannery chromium wastes. Proceedings of the 13th WSEAS International Conference on Computers. Rhodes, WSEAS Press, pp. 550-554

[7] Charvátová, H., Vašek, V., Drga, R., Křenek, J. (2011). Software application for solving of nonstationary temperature fields in twolayer plate. Annals of DAAAM and Proceedings of the International DAAAM Symposium Zadar, Croatia, pp. 359-360

[8] Kolomaznik, K,. Mladek, M., Langmaier, F., Janacova, D., Taylor, M., M.(2000). Experience in Industrial Practice of Enzymatic Dechromation of Chrome Shavings. JALCA, Vol. 94, pp. 55- 6. ISBN: 0002-9726 